\title{
La documentación del Patrimonio Intangible: propuestas para una base de datos
}

\author{
Victoria Quintero \\ Elodia Hernández \\ Antropólogas
}

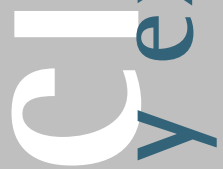

u

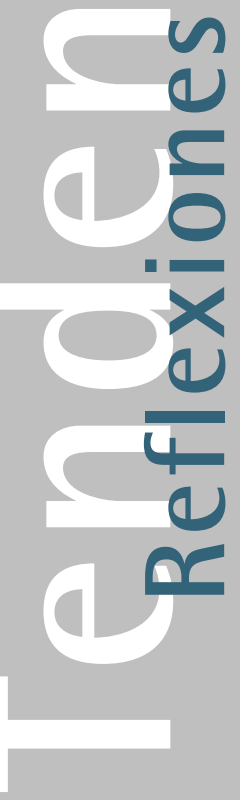

\section{Resumen}

Las nuevas definiciones en torno al Patrimonio Cultural y el desarrollo de las legislaciones en torno al patrimonio etnográfico plantean necesidades no contempladas hasta hoy, como los sistemas de documentación y las pautas a seguir para la protección del denominado patrimonio inmaterial. Sin entrar en debates teóricos, aunque con una conceptualización que sustenta este diseño, en este texto hemos intentado detallar los módulos y campos de una Base de Datos sobre Patrimonio Intangible en Andalucía como documento base de trabajo. Esta propuesta de documentación trata de cumplir dos objetivos fundamentales: Por una parte, la herramienta documental tratará de aunar los requisitos de información de los antropólogos con las necesidades de gestión y tutela de la Administración y de otros organismos; por otra parte, más que plantear un diseño acabado, lo que nos proponemos es abrir el debate e ir estableciendo algunos elementos de consenso entre administraciones y asociaciones que están llevando a cabo trabajos sobre este patrimonio.

\section{Palabras clave}

Patrimonio Etnológico / Patrimonio Intangible / Actividades de Interés Etnológico / Documentación / Base de Datos.

El concepto de Patrimonio, al evolucionar, se ha inclinado a favor de las significaciones por encima de los objetos, es decir, se considera que lo importante no es el objeto en sí sino los valores que lleva aparejados. Al mismo tiempo, la definición de qué pueda ser considerado patrimonio se ha ampliado considerablemente incluyendo hoy, además de los objetos, las actividades, las prácticas, los saberes, los rituales... Tal como indica la legislación estatal:
Se considera que tienen valor etnográfico y gozarán de protección administrativa aquellos conocimientos o actividades que procedan de modelos o técnicas tradicionales que procedan de una determinada comunidad (art. 47.3. LPHE 16/85)

El desarrollo de la actividad en torno al patrimonio en Andalucía, y en general en el contexto europeo, ha incrementado los diagnósticos y acciones de puesta en valor de elementos relacionados con actividades de interés etnográfico. Sin embargo, aún carecemos de herramientas y metodologías de gestión en torno a este patrimonio que podamos considerar suficientemente probadas. Esta propuesta de documentación en torno al denominado "patrimonio intangible" está aún en una fase inicial, pero trata de aportar una iniciativa que abra el debate. La exposición en público de los tanteos y resultados de la investigación y documentación puede ser una buena vía para avanzar entre todos. Creemos que es necesario establecer algunos elementos de consenso entre las administraciones, fundaciones y asociaciones que están llevando a cabo trabajos y catalogaciones en torno a este patrimonio!.

Por tanto, una advertencia necesaria es que este diseño está sujeto a cambios y a la espera de sugerencias que otros profesionales quieran realizar. Somos conscientes de que hay cuestiones que ni siquiera se han planteado por falta de práctica en la gestión de este tipo de elementos patrimoniales.

Quisiéramos señalar también que este diseño no se ha realizado como instrumento de investigación antropológica, sino que trata de aunar los requisitos del tratamiento de la información de los antropólogos con las necesidades de gestión y tutela de la administración y de otros organismos. Así pues, si bien se ha contemplado la necesidad de recoger la información con documentos sonoros o a través de imágenes fotográficas y por supuesto de audiovisuales, no es nuestro objetivo el tratamiento directo de esta información. Los registros que se den de alta en la base de datos no tienen porqué ser documentos empíricos "de primera mano", sino una información ya elaborada y analizada. Es decir, no tratamos de clasificar ni organizar por ejemplo, los datos registrados de diferentes informantes respecto al trabajo en una fábrica o las entrevistas referidas a la celebración de un ritual festivo2. Lo que se trata de recoger en la base de datos es una síntesis de esa documentación original en forma de "ficha" o registro que describa sus principales características. 
Cuando iniciamos este diseño nos impusimos al menos los siguientes requisitos:

- En primer lugar debía posibilitar su integración con el resto de las Bases de Datos que componen el SIPHA (Sistema de Información del Patrimonio Histórico de Andalucía), permitiendo el paso de los objetos a las actividades y viceversa. Es decir, debe relacionar automáticamente una actividad con el inmueble o inmuebles en los que se desarrolle y con los objetos muebles que la hacen posible, también debe ser posible la vinculación con otras actividades.

- En segundo lugar, debía ser un instrumento lo suficientemente flexible como para ser comprendido y utilizado por distintas administraciones y agentes dedicados a la gestión e investigación. Tenía que permitir almacenar una información mínima y también debía poder ser utilizada para trabajos más complejos.

- En tercer lugar, tendría que almacenar información sobre temáticas, en apariencia al menos, muy diferentes. Las actividades, prácticas y conocimientos de interés etnológico-patrimonial pueden ser desde manifestaciones festivas a espectáculos, saberes medicinales o procesos de trabajo3.

Otras consideraciones que hemos tenido en cuenta refieren a la heterogeneidad y dispersión de los datos que refieren a actividades de interés etnológico. Mucho de lo que conocemos procede de bibliografía, documentos audiovisuales o literatura gris. Esta información de carácter antropológico, sigue, no obstante, diferentes metodologías y no es automáticamente asumible en todos los casos. Otras de las posibles fuentes son las actuales campañas que se están llevando a cabo desde distintas entidades de desarrollo local. La ausencia de una perspectiva antropológica en muchos de estos casos supondrá ciertas limitaciones a estas fuentes de información.

También hemos reflexionado acerca del ámbito territorial que debíamos tomar como referencia. Se debe tener en cuenta que aunque existan distintas actividades identificables, por ejemplo, en cada municipio, a veces forman entramados de relaciones en el ámbito comarcal o supramunicipal. Por ejemplo, actividades de vinicultura identificadas en sólo dos municipio pero que se extienden, como saber hacer, a todo el ámbito comarcal. $\bigcirc$ un ciclo de fiestas de verano con actividades comunes y que definen un área de relación.

Los datos de contextualización territorial, como la demografía, datos económicos, estructura social, asociacionismo, etc. deben de estar contemplados en cada una de las entidades territoriales que se seleccionen. Ello significa que si se dan de alta actividades diferentes de una misma comarca, la información territorial seguirá siendo la misma. Por tanto pretendemos tener conexión con una futura Base de Datos de carácter Territorial aún por desarrollar.

Una actividad puede estar relacionada con uno o varios municipios. Como un mismo municipio puede pertenecer a diversas áreas territoriales (una man- comunidad, un parque natural, una comarca cultural, etc.) desde cada uno de los ámbitos territoriales se podrán visualiza las actividades de sus diversos municipios. No obstante, se pretende crear una relación especial entre la actividad y un "contexto territorial preferente". Se debe tener en cuenta que aunque existan distintas actividades identificables, por ejemplo, en cada municipio, a veces forman entramados de relaciones en el ámbito comarcal o supramunicipal.

El criterio respecto al "contexto territorial preferente" en que se dará de alta una actividad vendrá dado por la información disponible y las características de la misma. A pesar de que el criterio más adecuado para muchas de las actividades que se van a recoger sería el establecimiento de una selección unívoca que tiende más a un área comarcal o supracomarcal, la disponibilidad de los datos y la imposibilidad de generalizar desde un taller o municipio al resto del área, implica considerar diversas unidades heterogéneas. Es decir, que si en el Parque Natural de los Alcornocales existe información sobre el carboneo, se vinculará la actividad con esta entidad territorial, otro caso es que la información etnográfica disponible refiera sólo a tres talleres de dos municipios pero exista constancia de un modo de hacer similar extendido a toda la comarca pero en la que los talleres se han ido extinguiendo, en este caso se dará de alta la comarca.

Hemos articulado el diseño en cuatro grandes temáticas atendiendo, por una parte, a criterios de cierta vinculación similitud en cuanto a los datos y análisis a reflejar y, por otra parte, a facilitar la gestión y el uso de la base de datos en nuestro entorno andaluz. Queda configurado como sigues:

- Manifestaciones festivas: Celebraciones, rituales y fiestas.

- Formas de expresión y comunicación significativas: trovos, literatura cordel, danzas y bailes. Manifestaciones literarias, musicales, plásticas, escénicas...

- Oficios y modos de hacer: Actividades económicas de producción y transformación, producción de servicios. Se incluyen tanto los que tengan sentidos prácticos o rituales que supongan un saber hacer representativo de un colectivo. Ej. Carpintería de ribera, manipulación de hierbas medicinales, curanderismo, etc. Incluye también los saberes cotidianos.

- Cocinas: Referida a las actividades culinarias. Este ítem tendría que estar incluido en oficios y modos de hacer, pero por su especificidad e importancia en la valorización de algunas zonas, lo hemos separado.

La aplicación de patrimonio inmaterial se ha pensado organizada en tres módulos: un primero de ANÁLISIS, un segundo con datos de PROTECCIÓN y un tercero de DOCUMENTACIÓN. Aquí describiremos exhaustivamente el primero, remitiendo para los otros dos a los desarrollos de la Base de Datos Integrada del Patrimonio Histórico de Andalucía en cuyo contexto va a insertarse ${ }^{6}$. Sí que haremos menciones específicas de algunos campos que deben introducirse, por ejemplo respecto al planeamiento. 
El módulo de ANÁLISIS consta de tres pantallas: la primera de Identificación y localización; la segunda de Descripción y la tercera dedicado a Valoraciones y otros ámbitos significativos. Las cuatro grandes categorías de actividades contempladas permiten una preselección a través del campo "clasificación" (Manifestaciones festivas, Formas de expresión comunicativas, Oficios y modos de hacer, Cocinas) que hacen variar los tres formularios básicos. Tienen una estructura parecida en todos los temas aunque varían algunos campos según las necesidades de análisis de cada uno. Por ejemplo, la Identificación de los Oficios y Modos de Hacer tiene un campo clasificatorio denominado "Actividades" (se designarán los tipos por los que se pueda clasificar la actividad, use tesauro); sin embargo, en el caso de los Rituales y Manifestaciones Festivas la clasificación se hace a través del campo "Tipo de Fiesta" (Feria, romería, moros y cristianos, verbena, carnaval, navidad, semana santa, etc. Incluir los ritos de paso. Use tesauro) y el "Nivel de Integración" de la misma. En Formas de expresión comunicativas se clasifica a través de dos campos: "Actividad marco" (denominación de la actividad asociada o que contextualiza la acción o escenificación. Debe permitir visualizar otras actividades con las que se halle relacionado. La relación se establecerá internamente a través de los códigos) y "Tipología".

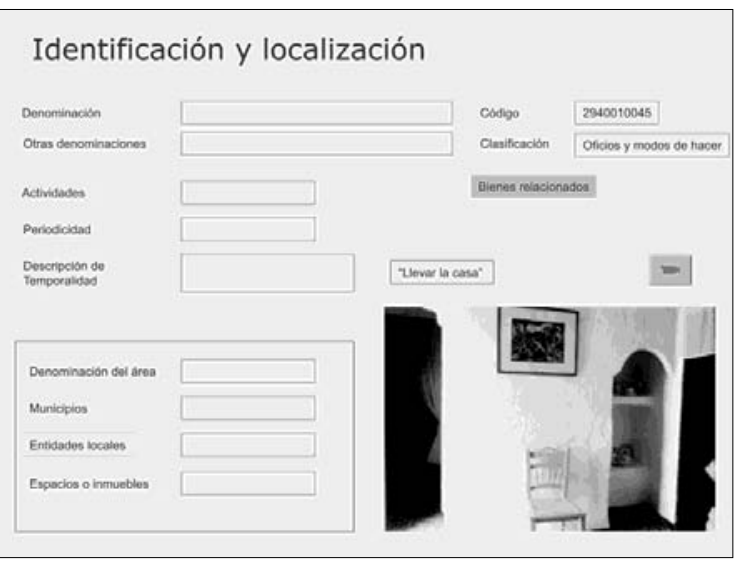

El módulo de PROTECCIÓN incluye una pantalla con Datos Administrativos de la Protección (Tipología jurídica, Clasificación, Expediente, Publicación, Justificación de la Protección, etc. y también campos que recojan las propuestas de protección); la segunda pantalla refiere al Planeamiento que existe en el área o áreas donde se desarrolla la actividad y además de los campos que se han desarrollado en la aplicación de patrimonio inmueble se incluirá un campo memo de "Recomendaciones" para a modificación de los mismos si fuera necesario para la salvaguarda de la actividad. No debemos olvidar que una de las fórmulas más eficaces de protección de muchas actividades está simplemente en facilitar que se continúen desarrollando, sobre todo descongestionando nuevos usos que puedan perjudicarles. La tercera pantalla que se propone es la de Delimitaciones en la que se incluyen las referencias territoriales que identifican claramente el área a la que afecta la actividad a proteger (Coordenadas UTM, justificación de la delimita- ción, manzanas/polígonos y parcelas). Estos datos son fundamentales para avanzar en la georreferenciación del Patrimonio Cultural andaluz. Ahora bien, no siempre será necesario incluir esta información puesto que a veces nos referiremos a un área territorial amplia, sin que se localice en ningún punto concreto y otras veces nos referiremos a inmuebles concretos, cuyos datos de georreferenciación deben incluirse como datos de la edificación.

El módulo de DOCUMENTACIÓN tendrá las mismas características que las versiones de la Base de Datos Integrada de Patrimonio Inmueble, contando con una pantalla de Documentación, otra de documentación Gráfica y una tercera de Bibliografía. La descripción de los materiales sonoros o audiovisuales, calificados como "Materiales Especiales" tendrán un mayor desarrollo tal como está previsto en la Base de Datos Documental del Patrimonio Histórico. Además, se señalará convenientemente cuáles son las referencias que se consideran fuente de registro del bien.

\section{BORRADOR DE LA APLICACIÓN DE ACTIVIDADES DE INTERÉS ETNOLÓGICO. MÓDULO DE ANÁLISIS}

\section{Pantalla de identificación y localización}

- Código: Campo numérico. Se seguirá una numeración similar que para el resto de los bienes (290130004).

- Clasificación: Campo cerrado, listado asociado. Manifestaciones festivas y rituales; Oficios y modos de hacer; Formas de expresión significativas; Gastronomía. Este campo actuará como filtro variando diversos campos y módulos en la base de datos dependiendo de cual se seleccione.

- Denominación: Campo de texto. Se designará el nombre de la actividad más la zona. Ej. Actividad salinera en Baeza; Tonelería Jerezana. En el caso de las manifestaciones festivas se dará de alta el nombre oficial con que se conoce, ej. Semana Santa de Puente Genil o Romería en Honor a la Santísima Virgen de la Peña.

- Otras denominaciones: Se darán de alta otras designaciones y nombres populares.

\section{Localización}

La actividad se consignará en el lugar donde concretamente se realiza, independientemente de su ámbito de acción en el caso de manifestaciones festivo-ceremoniales y formas de expresión. Si se trata de un saber compartido por diversos pueblos de un territorio, se consignará la entidad territorial correspondiente.

- Entidad territorial (Comarca, Mancomunidad, Espacio Natural, Area Metropolitana, Municipio, Otras Entidades); Listado, un solo valor.

- Área: Nombre de la entidad territorial, ej. Mancomunidad Alhama - Temple. Listado asociado abierto. 
- Municipios: Municipio a que se aluda o Relación de municipios incluidos en el área seleccionada. Listado asociado tesauro. Uno o varios valores.

- Entidades Locales Menores. Listado asociado. Se cumplimentará solo cuando sea necesario señalar éstas. Uno o varios valores.

- Inmuebles o espacios en los que se desarrolla la actividad: El criterio puede ser diferente dependiendo del tipo de actividad. Por ejemplo podría ser Talleres alfareros para la alfarería de una comarca (la relación de inmuebles dependería de los códigos relacionados) o las viviendas respecto a la gastronomía cotidiana. En el caso de una fiesta deben consignarse los lugares donde principalmente se celebra (Ermita de San Blas, Real de la Feria, etc.) Cuando refiera a un sitio concreto puede abrirse un campo de dirección asociado. Campo de texto que admitirá varios valores Ej. Ermita de la Virgen de la Peña, Centro Urbano de la Puebla de Guzmán.

- Dirección: Ej. El Cerro del Aguila.

- Imagen o vídeo.

\section{Botones}

- Bienes Relacionados: Conexión con los bienes inventariados que se relacionen con esta actividad. Deben diferenciarse muebles, inmuebles y actividades. Aparecerá un listado con la denominación y tipología de cada uno de los bienes. Debe posibilitar la conexión con los registros correspondientes.

\section{Campos específicos para cada clasificación}

\section{Oficios y modos de hacer}

Actividades: Campo cerrado. Listado Tesauro. Se designarán los tipos por los que se pueda clasificar la actividad.

\section{Temporalidad}

- Periodicidad: Listado asociado: anual, estacional, mensual, continua, cada $x$ años (para fiestas y modos de hacer), ocasional.

- Descripción de la temporalidad. Campo memo.

Estos dos campos están conectados. El primero debe admitir varios valores y el campo memo será dependiente de éste.

\section{Manifestaciones festivas}

- Tipo de fiesta: Campo cerrado. Listado tesauro. Feria, romería, moros y cristianos, verbena, carnaval, navidad, semana santa, etc. Incluir los ritos de paso.

- Nivel de integración (de la fiesta): Campo cerrado. Listado tesauro. Referirá el nivel de integración comunal, supracomunal o intracomunal.

\section{Temporalidad}

- Periodicidad: Listado asociado: anual, estacional, mensual, continua, cada $x$ años (para fiestas y modos de hacer), ocasional.

- Fechas. Será un campo de texto, pues las fechas de las celebraciones a menudo son aproximadas o responden a criterios como el último fin de semana del mes o "en torno al día I 5 de Agosto", etc. También ha de tenerse en cuenta que pueden ser móviles (trasladarse de fecha puntualmente para no coincidir con la de un pueblo vecino).

\section{Formas de comunicación significativas}

- Actividad marco: Denominación de la actividad asociada o que contextualiza la acción o escenificación. Debe permitir visualizar otras actividades con las que se halle relacionado. La relación se establecerá internamente a través de los códigos.

- Tipología: Campo texto con listado asociado. Tipo de expresión comunicativa

\section{Cocinas}

- Actividad marco: Denominación de la actividad asociada o que contextualiza la acción. Debe permitir visualizar otras actividades con las que se halle relacionado.

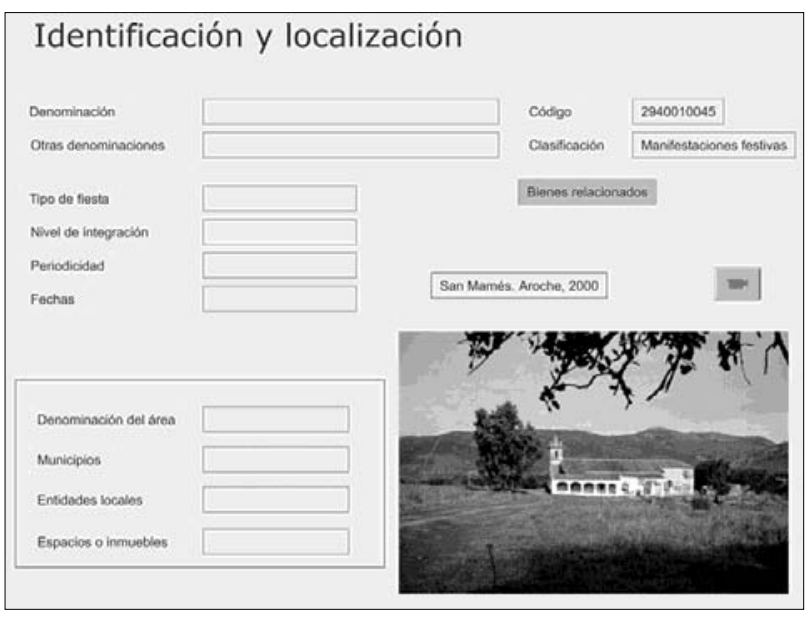

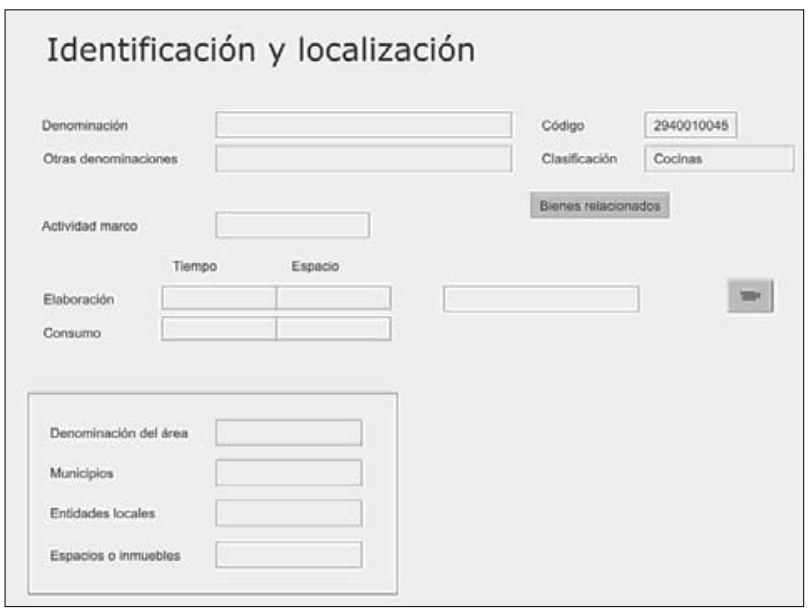



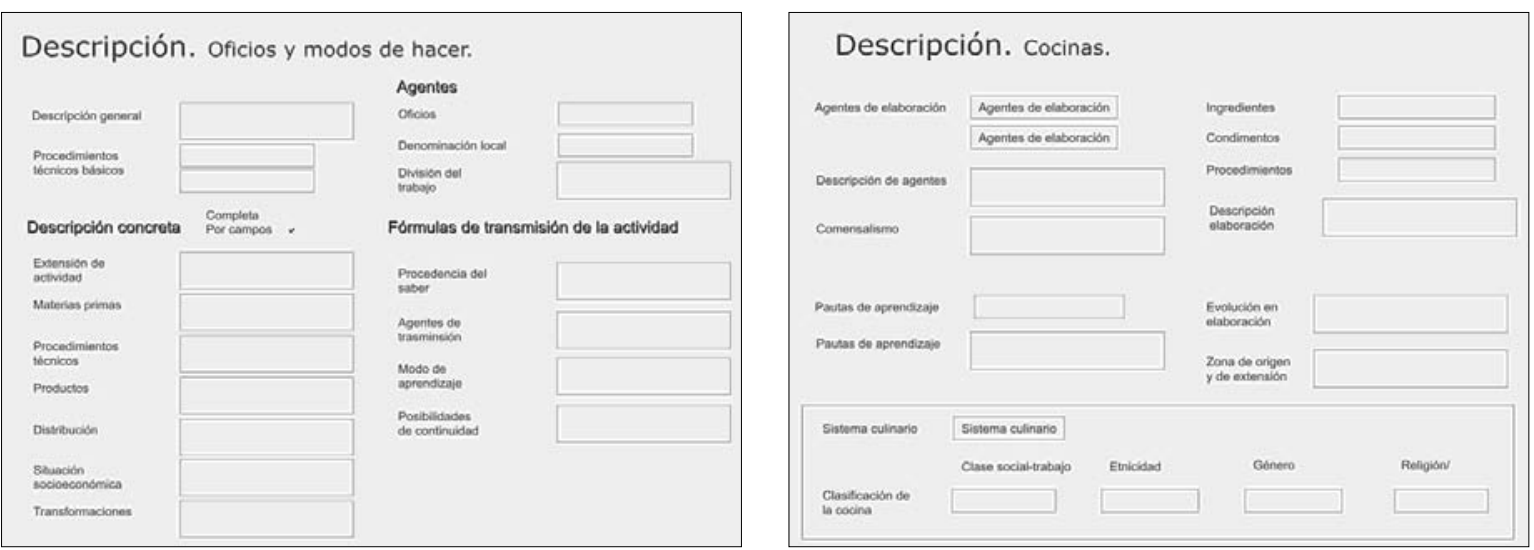

Pantalla 4 Pantalla 5

Temporalidad

\begin{tabular}{l|l|c|l|c}
\hline \multicolumn{2}{c|}{ TIEMPO } & \multicolumn{2}{c}{ ESPACIOS } \\
\hline DE ELABORACIÓN & (tres valores determinados)* & $\downarrow$ & (valores determinadas )* & $\downarrow$ \\
\hline DE CONSUMO & (tres valores determinados)* & $\downarrow$ & (valores determinadas )* & $\downarrow$ \\
\hline OBSERVACIONES & & & \\
(Campo texto que matiza la información) & &
\end{tabular}

* (Valores coincidentes: Durante la actividad; En vísperas de la actividad; Posterior a la actividad. Se trata de calificar los días de elaboración y consumo que tienden a ser diferentes aunque a veces coincidan). que matiza la información)

- (Listado de valores extraídos de inmuebles de ámbito edificatorio y territorial del tesauro: Viviendas, Recintos feriales, Edificios de hostelería....).

\section{Pantalla de descripción}

\section{Oficios y modos de hacer}

\section{A. DESCRIPCIÓN}

- Descripción genérica: Botón posiblemente conectado con hipervínculo (o cualquier otro tipo de conexión interna). Será la descripción de la actividad, que se mantendrá idéntica para todas aquellas que refieran a un mismo saber hacer (ej. la tonelería, la crianza del vino, la alfarería en blanco, etc.). El nivel de precisión vendrá dado por las diferencias sustanciales de los procedimientos. Es decir, puede ser interesante dar de alta por una parte la elaboración de los vinos blancos de crianza y por otro lado los afrutados, si los procedimientos variaran sustancialmente; pero si la información disponible simplemente señala una variante en un momento puntual de proceso de producción quizá se diera de alta sólo uno. Será cuestión de analizar cada caso y de modificarlo cuando se disponga de otra información. Se deberá prever la posibilidad de estas modificaciones teniendo en cuenta que entonces se vincularán distintas informaciones a registros que inicialmente dependían de uno solo.

- Procedimientos técnicos básicos. Este campo irá asociado al anterior. Listado tesauro. Un campo para cada procedimiento. Varios valores.

- Descripción concreta de la actividad: Deben incluirse sólo las VARIACIONES con respecto al genérico. Este campo podrá desdoblarse, pudiendo ser visualizado como completo o por campos.
En cada uno de los campos se tendrá en cuenta el ASPECTO EVOLUTIVO, es decir, se irán mencionando los cambios más destacables que hayan tenido lugar.

- Distribución de la actividad en la zona. Sería de carácter introductorio, Ej. En Montilla hay ocho tonelerías en activo. Memo

- Materias primas y fuentes de energía. Referirá a las variantes concretas en la zona de análisis. Ejemplo variantes de vides, tipo de barros utilizados, etc. Memo.

- Descripción de las variantes en los procedimientos técnicos: En caso de que no las haya se consignará que "el proceso sigue las mismas pautas descritas anteriormente". O una frase similar. El objeto de la misma es no romper la redacción del campo "completo" en el caso de que sólo se cumplimente alguno de ellos. Memo

- Productos que se obtienen: Referirá a las variantes. Por ejemplo en alfarería se consignará el tipo de vasijas y objetos que se fabrican. También es susceptible señalar las cantidades o volumetría de la producción. Memo

- Distribución y comercialización. Desde donde se distribuye el producto, que área de venta tiene, en que ferias o eventos se promociona, etc. Memo

- Evolución socioeconómica de la actividad: Referirá a la rentabilidad, prestigio conferido etc. y variaciones en estas en el tiempo. También se consignará la relación de la actividad con otras producciones o actividades de la comarca. Ej. El auge de la alfarería en esta zona coincidió con una masiva exportación de aceites a principios de siglo, ello influyó en el diseño y tamaño de las mismas, que ha ido variando... Memo 
Agentes

- Oficios: Listado tesauro por oficios. Debe verse si conviene designar un solo oficio o las distintas denominaciones internas del mismo. Varios valores.

- Denominación local: Denominación local del oficio o categoría.

- División del trabajo. Memo. Sistema de jerarquización del trabajo y organización del mismo.

\section{Fórmulas de transmisión de la actividad}

- Procedencia del saber hacer: Memo. Cuando esté documentada la procedencia de otra zona o escuela de artesanos, taller de origen etc. se señalará la misma.

- Modo de transmisión (dos campos): Se referirán al modo en que aprendió la persona que ejerce la actividad actualmente. Se referirá al responsable principal de la actividad en talleres y oficios (maestro) y a la fórmula predominante en los casos más colectivos. Las diferencias en el aprendizaje para los procesos con una fuerte división del trabajo se referirán en el campo memo.

- Transmisión: Campo cerrado. Términos posibles: Padres-hijos, maestro-aprendiz, escuela, cuadrilla o en el mismo proceso de producción, etc.

- Proceso de transmisión del aprendizaje: Memo. Se describirá la forma en que se transmite el conocimiento, las etapas por las que se pasa, el tiempo que lleva el paso de un estatus a otro, etc. Si son varios sistemas (según la división del trabajo) se irá describiendo ordenadamente cada uno de ellos.

- Fórmula de continuidad: Memo. Se refiere a las nuevas formas de transmisión, si es que están cambiando o si el proceso de transmisión ha desaparecido.

\section{Manifestaciones festivo-ceremoniales}

- ¿Se celebra en la actualidad? Sí; No

Descripción Por campos $X \quad$ Completa

- Preparativos: Memo

- Desarrollo de la fiesta. Memo

- Actividades secundarias. Memo

- Organización del espacio. Memo.

Procesiones, desfiles o representaciones públicas:

Etiqueta que da entrada a tres campos interrelacionados; deben admitir todos los valores necesarios.

- Denominación concreta: Texto. Refiere al nombre del acto, ej. Desfile de caballistas, Comida de pobres, etc. Por defecto debe aparecer UN NIVEL GENERAL con la denominación de la fiesta.

- Tipo: Listado de elementos de tesauro. Señalar la tipología del acto. Ej: Procesión religiosa; procesión civil (desfile); espectáculo taurino; Cabalgata de Reyes; Nacimiento; Pastorada; Auto sacramental; Moros y cristianos; Acciones con animales; Hoguera; Quema de judas; Juego.

- Descripción del acto o representación. Memo.

\section{Agentes:}

Los campos a que da entrada esta etiqueta deben estar relacionados con los anteriores.

- Organizadores de la fiesta. Dos campos:

- Organizadores I: Texto, campo cerrado. Listado de tesauro. Uno o varios valores.

- Organizadores 2: Campo memo.

- Modo de financiación de la fiesta. Memo.

- Participantes: Memo

Área de atracción de la fiesta.

- Area participación: Texto. Elegir un valor: Supraprovincial; Supramunicipal.

Cada uno de estos campos da entrada a una tabla de provincias y municipios. En el caso de que sea supraprovincial o supramunicipal se elegirán las provincias correspondientes y dentro de éstas los municipios incluidos. En el caso inframunicipal se admitirá un campo de texto para introducir las barriadas correspondientes.

\section{Formas de comunicación y expresión significativas}

- Descripción. Memo.

Agentes

- Tipo de agentes. Listado de tesauro, seleccionar un valor

- Intérpretes: Texto, nombres y apellidos

- Descripción de los intérpretes. Memo

- Autoría. Texto, nombre o anónimo

\section{Modo de transmisión}

(Dos campos): Se referirán al modo en que aprendió la persona que ejerce la actividad actualmente

- Transmisión: Campo cerrado. Términos posibles: Padres-hijos, maestro-aprendiz, escuela, en la actividad, etc.

- Modo de transmisión: Memo.

- Fórmula de continuidad: Memo. Se refiere a las nuevas formas de transmisión, si es que están cambiando o si el proceso de transmisión ha desaparecido.

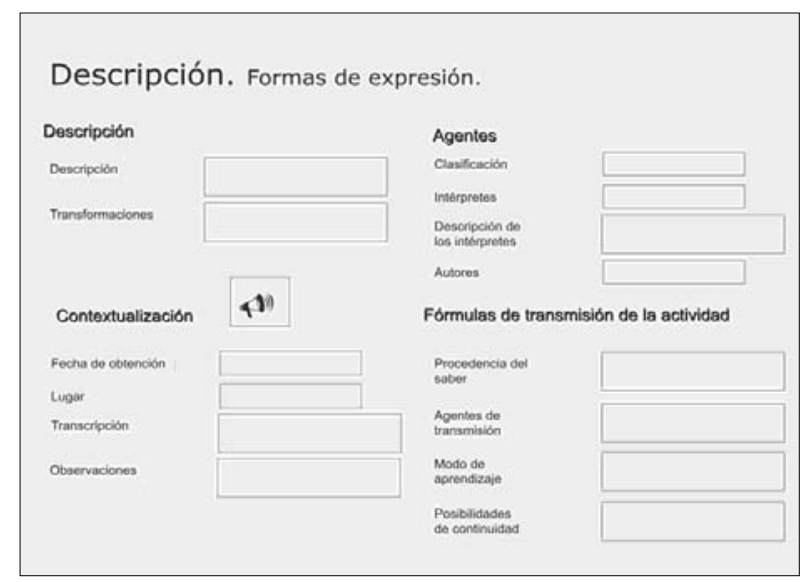




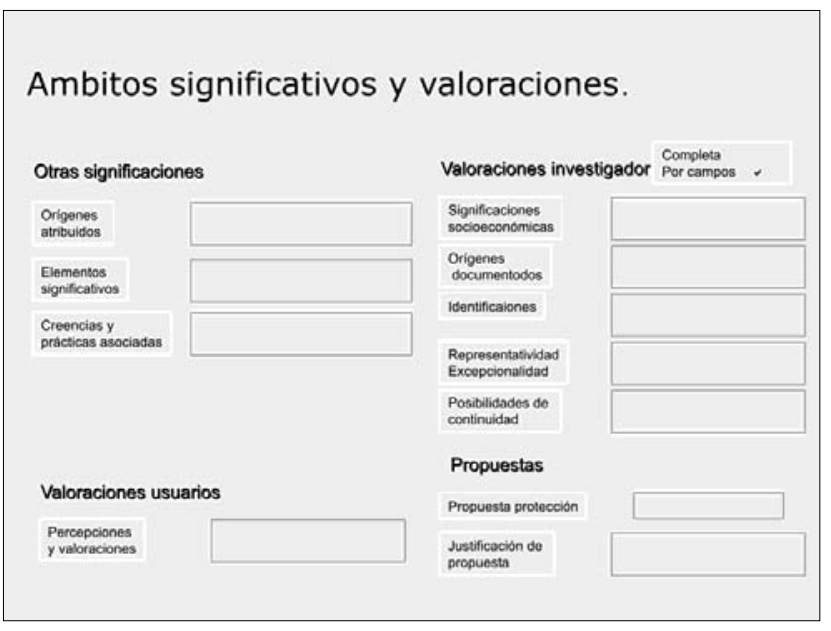

Pantalla 7

\section{Sistema culinario}

- Sistema culinario de pertenencia: Listado asociado.

- Cocinas: Clasificación de las cocinas según variables de clase social/trabajo, etnia, género y religión.

\section{Pantalla de otros ámbitos significativos y valoraciones}

Otros ámbitos significativos

- Orígenes atribuidos. Memo.

- Elementos significativos relacionados: Memo. Se incluirán dichos, cantes, rituales u otros elementos relacionados directamente con la actividad. Más que las letras o las descripciones de los rituales se mencionará la formula genérica. Ej. Se canta un tipo de fandango muy ajotado con letras propias de la zona y la fiesta (coplas del Artillerito) - Piedras Albas.

- Creencias y prácticas asociadas: Memo. Sobre las condiciones de producción, etc. Ej. "El horno no se debe encender con luna llena porque las piezas se acarran". O "los hombres son los que trabajan en la zona de carga porque físicamente resisten más estas tareas".

\section{Valoraciones}

- Valoración de los usuarios. Memo

- Valoración del investigador. Completa o por campos. - Significación socio-económica de la actividad en el contexto local. Memo. Referirá al ámbito tradicional en el que se insertaba la actividad, su significado e interrelación con otros ámbitos productivos, el peso económico y laboral en la localidad o comarca. Es importante diferenciarlo del campo de la "situación económica y social de la actividad" que refiere a datos exclusivamente actuales. Cuando coincidan ambos aspectos se tendrá en cuenta la evolución.

- Orígenes documentados: Memo

- Identificaciones construidas en torno a la actividad. Memo

- Excepcionalidad o representatividad en el contexto autonómico o estatal: Memo

- Posibilidades de continuidad de la actividad: Memo

\section{Transmisión}

- Evolución en la elaboración: Campo memo. Lo que se conoce de las variaciones con el tiempo en la elaboración de los platos.

- Pautas de aprendizaje: Campo cerrado con términos asociados (de padres a hijos; de madres a hijas, de maestro a aprendiz; escuelas; cuadrilla...) y a continuación observaciones.

- Zona de origen y de extensión: Campo memo. Procedencia del saber y las fórmulas de elaboración.

Nota de las autoras: Las reflexiones que se vierten aquí, así como las propuestas que se hacen, son fruto del trabajo en el ámbito del Centro de Documentación del IAPH realizado por Elodia Hernández y Victoria Quintero. Hemos de agradecer, sin implicarlo en los errores que se hayan podido cometer, la dedicación de Juan Agudo a comentarnos y criticar constructivamente algunos bocetos respecto a esta Base de Datos. 


\section{Bibliografía}

Díaz Iglesias, J.M. y otros (200 I): "La Base de Datos de Ciudades Históricas de Andalucía: un instrumento para la ordenación del Territorio y la protección del Patrimonio Histórico" en PH Boletín n³7, pp. 215-222.

Hernández León, E. (2002): "Territorio y patrimonio" en Hernández (ed.): Antropología y patrimonio. Cuaderno técnico n XIII. Consejería de Cultura, Granada. En prensa.

Fernández Cacho, S., Mondéjar de Quincoces, P. y Díaz Iglesias, J.M. (2000): "Arqueos. Un modelo andaluz de gestión de la información arqueológica" en PH Boletín n³0, pp. I 43- 149.

(2002): Análisis del Patrimonio Arqueológico en el ámbito andaluz" en Fernández Cacho (ed.): Arqueos. Sistema de Información del Patrimonio Arqueológico de Andalucía. Cuaderno técnico $n^{\circ}$ XII. Consejería de Cultura, Granada.
Muñoz Cruz, V. (200 I): "Hacia un Sistema Integrado del Patrimonio Histórico de Andalucía: la base de datos del Patrimonio Inmueble" en PH Boletín n³7, pp.223-229.

Quintero Morón, V. (2002): "El Patrimonio Inmaterial ¿Intangible?" en Hernández (ed.): Antropología y patrimonio. Cuaderno técnico $n^{\circ}$ XIII. Consejería de Cultura, Granada. En prensa.

Orsatti, C. (2000): "How to Constitute an Archive of Oral Memory and Identity Within the Framework of A.P.T.O.: A few methodological proposals" [36 paragraphs]. Forum: Qualitative Social Research [Online Journal], I (3). Available at: http://qualitative-research.net/fqs/fqs-eng.htm [Date of access: "30/I I/200 I].

\section{Notas}

I. Con estos mismos objetivos de ir abriendo el debate y establecer puntos de consenso se ha publicado una reflexión, por otra parte siempre necesaria cuando se trata de desarrollar una herramienta, que gira más en torno a los conceptos de patrimonio intangible. Véase Quintero, 2002.

2. Son numerosas las herramientas de gestión de la información oral que se están desarrollando en diversos centros de investigación etnológica, con especial consideración a los criterios de accesibilidad y preservación de la intimidad de las personas que aparecen en estos documentos (Orsatti, 200 I). También se está avanzando en la combinación de distintas fuentes de información (videos, fotografías, documentos sonoros, transcripciones, observaciones, etc.) trabajando con documentos multimedia.

3. Una enumeración no exhaustiva incluiría: ritos de paso, fiestas, actividades económicas de producción y transformación, cuentos y leyendas, cantes y coplas, danzas y bailes, prácticas de sociabilidad formal e informal, prácticas devocionales, creencias mágico-religiosas, espectáculos, etc.

4. En el Centro de Documentación del IAPH se están desarrollando investigaciones en torno al análisis del Patrimonio en el Territorio. Algunas de las premisas conceptuales para este análisis pueden verse en Hernández, E. 2002. El área de arqueología realizó un ensayo pionero respecto a la elaboración de herramientas para el análisis en el territorio, que ya ha dado resultados parciales pero aún está sin concluir (Fernández, S; Mondéjar, P, y Díaz JM: 2000 y 2002). Otro de los avances en esta dirección lo representa el proyecto de la Base de Datos del Patrimonio Histórico de Andalucía (Díaz Iglesias et alt., 200 I). Actualmente un proyecto sobre el terreno para diseñar una metodología de planificación del patrimonio en el territorio lo representa el Proyecto Alianzas para la conservación que dirige Pedro Salmerón.

5. Puede compararse esta clasificación con la recientemente publicada por la Unesco. Según este organismo las Obras Maestras del Patrimonio Oral en Inmaterial pueden subdividirse en Espacios Culturales (Espacios y Sitios) y en Formas de Expresión Cultural Tradicional y Popular. Respecto a ésta última la Unesco ofrece la siguiente subdivisión: I. Literatura oral: Mitos y plegarias; Epica y genealogía; Cuentos y leyendas; Dichos; Encantamientos; Canciones; Conocimiento del ecosistema. II. Técnicas Corporales: Rituales; Performance; Deportes y artes marciales; Música; Mimo; Lenguaje de signos. III. Saber Hacer: Técnicas de Producción; Técnicas de aprendizaje; Hábitos alimenticios y artes culinarias; Oficios, artesanías; Técnicas curativas.

6. Las características de este sistema integrado pueden verse en Muñoz Cruz, 1998 y 2001.

7. Siempre se dará de alta la fiesta principal y no los eventos o actos destacables. Por ejemplo, si se quisiera consignar la Quema del Judas de X, se dará de alta la Semana Santa en que se inserta dicha fiesta y será en el módulo descripción, entre las procesiones o representaciones significativas, donde se describirá este evento concreto. 